\title{
Prediction of endurance running performance for middle-aged and older runners
}

\author{
Nobuo Takeshima and Kiyoji Tanaka* \\ College of General Education, Nagoya City University, 1-1 Mizuho, Mizuho-ku, Nagoya 467 and *Institute of \\ Health and Sport Sciences, University of Tsukuba, 1-1-1 Tennodai, Tsukuba 305, Japan
}

\begin{abstract}
The purpose of this study was to develop regression equations that would sufficiently predict the endurance running performance (ERP) of middle-aged and older runners ( $n=55,43-79$ years). Among many independent variables which were selected as possible predictors of the ERP, oxygen uptake corresponding to the lactate threshold $\left(\dot{V} \mathrm{O}_{2} @ L T\right)$, or age was found to be the single best predictor. Some variables representing training habits correlated significantly but only moderately with the ERP. Linear multiple regression equations developed in this study were:

$V_{5 k m}=4.203+0.054 X_{1}-0.028 X_{2}(r=0.87)$
$V_{5 k m}=4.436+0.045 X_{1}-0.033 X_{2}+0.005 X_{3}(r=0.89)$
$V_{10 k m}=4.252+0.042 X_{1}-0.026 X_{2}(r=0.79)$
$V_{10 k m}=4.371+0.037 X_{1}-0.031 X_{2}+0.005 X_{3}(r=0.82)$
$V_{M}=3.207+0.048 X_{1}-0.022 X_{2}(r=0.91)$
$V_{M}=3.707+0.038 X_{1}-0.031 X_{2}+0.005 X_{3}(r=0.93)$
\end{abstract}

where $V_{5 \mathrm{~km}}, V_{10 \mathrm{~km}}$ and $V_{M}$ are the mean running velocity at $5 \mathrm{~km}, 10 \mathrm{~km}$ and marathon races, respectively, and $X_{1}=$ $\dot{V}_{\mathrm{O}_{2}} @ \mathrm{LT}\left(\mathrm{ml} \mathrm{kg}^{-1} \min ^{-1}\right), X_{2}=$ age (year), and $X_{3}=$ average running duration per workout (min). We suggest that the ERP of middle-aged and older runners can be predicted from a linear combination of $\dot{V}_{\mathrm{O}_{2}} @ \mathrm{LT}$ and age or a combination of these variables plus average running duration per workout.

Keywords: middle-aged and older runners, prediction of endurance running performance, lactate threshold, training habits

An accumulated body of literature has demonstrated that success or failure in competitive distance running has been attributed primarily to the state of maximal oxygen uptake $\left(\dot{V}_{\mathrm{O}_{2} \text { max }}\right)$, oxygen uptake


ning economy at a standardized velocity, muscle fibre composition and others. The highest correlation $(r=$ -0.83 ) of performance in 4.7 mile cross-country running detected by Costill $^{1}$ has been found with $\dot{V} \mathrm{O}_{2 \text { max }}$ from among many possible prerequisites. An even higher correlated relationship $(r=0.91)$ has been further described by Costill et al. ${ }^{2}$ between $\dot{V}_{\mathrm{O}_{2} \max }$ and 10 -mile running performance in 16

Address for correspondence: Dr N. Takeshima, College of General Education, Nagoya City University, 1-1 Mizuho, Mizuho-ku, Nagoya 467, Japan well-trained runners, aged 25-48 years. However, Allen $e t a l .^{3}$ have reported that, despite having $9 \%$ lower $\dot{V}_{\mathrm{O}_{2} \text { max }}$ values, master runners (mean(s.d.) age $=56(5)$ years) have the same performance in $10-\mathrm{km}$ running as young runners (25(3) years) matched in terms of training distance, training pace and type of training.

Recent studies using a relatively homogeneous sample of highly trained runners in terms of both distance running performance and $\dot{V}_{\mathrm{O}_{2} \max }$ have obtained low-to-moderate correlations $(r=-0.12$, -0.18 and -0.58$)$ between $\dot{V}_{\mathrm{O}_{2} \max }$ and race times ${ }^{4-6}$. In other studies, $\dot{V}_{2} @ L T$ and/or running velocity corresponding to LT have been postulated as a better (possibly the single best) determinant of endurance running performance (ERP) than a number of prerequisites including $\mathrm{VO}_{2 \max }{ }_{7-13}$.

The popularity of strenuous events such as the marathon and triathlon has increased tremendously over the last decade, such that the prerequisites for competing in these events should be investigated. It is logically assumed that a combination of several prerequisites such as $\dot{V}_{2} @ \mathrm{LT}, \dot{\mathrm{O}_{2} \max }$, age, muscle fibre type, body composition or training habits is critical to the optimal prediction of ERP. Slovic ${ }^{14}$ has indicated that there are systematic relationships between personal characteristics, training habits and performance in the marathon for young runners. However, little effort has been made to determine with a multivariate statistical procedure the relationship of these prerequisites to the ERP for middle-aged and older runners.

In as much as the runners consist of middle-aged and older individuals, it seems appropriate that age and training habits should also be included in a series of independent variables. The purpose of this study was to develop regression equations that would sufficiently predict ERP from age, $\dot{V O}_{2} @ L T$ or $\dot{V}_{\mathrm{O}_{2} \max }$ and training habit-related variables for middle-aged and older runners.

\section{Materials and methods}

\section{Subjects}

Fifty-one male, competitive runners, with a mean(s.d.) age of 57.3(8.9) years (43-79 years), served as subjects in this study. Statements of informed consent were obtained from each subject 
prior to the tests. The procedures used in this study were approved by the University of Tsukuba HealthFitness Ethics Committee and were in accordance with the policy of American College of Sports Medicine for human experimentation. Mean(s.d.) values for the 51 runners were: stature $163.5(4.5) \mathrm{cm}$, weight $58.9(5.9) \mathrm{kg}$ and estimated body fat $11.5(3.0) \%$. The percentage of body fat was derived from body density ${ }^{15}$, which was determined by the sum of the triceps and subscapular skinfolds ${ }^{16}$. Body mass index (BMI) which was calculated as (weight/ stature $^{2}$ ) $\times 10^{4}$ mean(s.d.) $22.0(1.8)$.

\section{Training habits}

The runners has been training mean(s.d.) 5.4(1.2) days week ${ }^{-1}$ for competitive distance or marathon events for an average of 13.1(7.3) years before the tests. Current running distance per week and current duration of training per day averaged mean(s.d.)

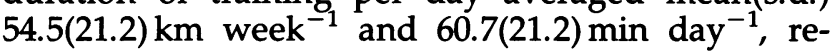
spectively. Considering s.d.'s for these training characteristics, it is likely that both the training experience and the weekly running distance varied greatly among the runners, while there were relatively small individual differences in the training frequency.

\section{Measurement of lactate threshold (LT) and $\dot{V}_{\mathbf{O}_{\max }}$}

The $\dot{V} \mathrm{O}_{2} @ \mathrm{LT}$ and $\dot{V} \mathrm{O}_{2 \max }$ were measured during a continuous cycling exercise test on a Monark cycle ergometer. There is agreement among most researchers the $\dot{V}_{\mathbf{O}_{\text {max }}}$ elicited during normal cycle ergometer work is somewhat lower than that measured during uphill running on the treadmill when subjects are not well trained for cycling. Nevertheless, the $\dot{V}_{\mathrm{O}_{2} \max }$ was measured on a stationary cycle ergometer in the present study. The reason for adopting the cycle ergometer test was that electrocardiograms are much more accurately recorded during cycling exercise compared to treadmill running at relatively high speeds. Blood samples can also be more easily and more accurately obtained during cycling exercise as compared with treadmill running. The test started with 4 min unloaded cycling at 60 r.p.m. Following the warm-up, a work rate of $15 \mathrm{~W}$ was administered for the 5 th min and thereafter increased by $15 \mathrm{~W}$ every minute until volitional exhaustion. All measurements of expiratory gases were determined by standard techniques of opencircuit spirometry, using a Mijnhardt Oxycon System OX-4 (The Netherlands). Gas analysers for $\mathrm{O}_{2}$ and $\mathrm{CO}_{2}$ involved in the processor system were calibrated immediately prior to and after each test with standard gases of known concentrations.

For detection of LT, a series of blood samples $(1 \mathrm{ml}$ each) were taken from the antecubital vein every minute during exercise. Blood lactate (La) determination was performed by the enzymatic electrode method $^{17}$ with an Omron-Toyobo lactate analyser HER-100. LT was detected as the point in exercise of increasing intensity at which La abruptly increased in a non-linear (disproportionately high) fashion. For discerning the point at which the increase of La concentration became non-linear, the log-log transformation method proposed by Beaver et al. ${ }^{18}$ was used.

The highest value of $\dot{V}_{2}$ recorded during the test was considered as $\dot{V}_{\mathrm{O}_{2} \text { max. }}$ All the subjects reported here met at least two of the following three criteria for $\dot{V}_{2 \max }$ documentation: (1) the $\dot{\mathrm{V}}_{2}$ plateaued $\left(<150 \mathrm{ml} \mathrm{min}^{-1}\right)$ despite increasing exercise intensity; (2) the highest respiratory exchange ratio was greater than 1.10; and (3) the highest heart rate was greater than $90 \%$ of the age-predicted maximal heart rate (220 - age). Forty-seven out of the 51 subjects met all the three criteria. Time taken to reach $\dot{V}_{\mathrm{O}_{2} \text { max }}$ ranged from $15-23 \mathrm{~min}$.

\section{Statistics}

A linear multiple regression analysis, with the stepwise procedure, was applied to the correlation matrix in order to extract a combination of several variables, which in turn provided the optimal prediction of each distance running performance. Dependent variables were mean running velocity at $5 \mathrm{~km}\left(\mathrm{~V}_{5 \mathrm{~km}}\right), 10 \mathrm{~km}\left(\mathrm{~V}_{10 \mathrm{~km}}\right)$, and marathon $\left(\mathrm{V}_{\mathrm{M}}\right)$. Standard error of estimate (SEest) was computed as the square root of the unpredictable portion of the variance in a set of observations; that is, SEest = $\sqrt{ } \Sigma\left(Y-Y^{\prime}\right)^{2} / n$, where $Y$ is the actual score, $Y^{\prime}$ is the predicted score from the regression line, and $n$ is the number of subjects. Significant correlations were only accepted when $P$ values were less than 0.05 .

\section{Results}

A summary of the selected physiological, anthropometric and running performance characteristics of the subjects is given in Table 1. Results of the Pearson

Table 1. Descriptive statistics for selected variables

\begin{tabular}{|c|c|}
\hline & Mean(s.d.) \\
\hline Age (year) & $57.3(8.9)$ \\
\hline Stature $(\mathrm{cm})$ & $163.5(4.5)$ \\
\hline Weight (kg) & $58.9(5.9)$ \\
\hline $\mathrm{BMI}^{\circ}$ & $22.0(1.8)$ \\
\hline Body fat (\%) & $11.5(3.0)$ \\
\hline HR (beats $\min ^{-1}$ ) & $62.8(9.0)$ \\
\hline $\mathrm{SBP}(\mathrm{mmHg})$ & $139.0(14.0)$ \\
\hline $\mathrm{DBP}(\mathrm{mmHg})$ & $80.9(9.8)$ \\
\hline$\dot{V}_{\mathrm{O}_{2}} @ \mathrm{LT}\left(\mathrm{ml} \mathrm{kg}^{-1} \mathrm{~min}^{-1}\right)$ & $27.7(6.3)$ \\
\hline $\begin{array}{l}\dot{V}_{\mathrm{O}_{2 \max }}\left(\mathrm{ml} \mathrm{kg}^{-1} \mathrm{~min}^{-1}\right) \\
\text { Training characteristics }\end{array}$ & $47.1(8.3)$ \\
\hline experience (year) & $13.1(7.3)$ \\
\hline distance $\left(\mathrm{km}\right.$ week $\left.{ }^{-1}\right)$ & $54.5(21.1$ \\
\hline duration $\left(\min\right.$ day $\left.^{-1}\right)$ & $60.7(20.7)$ \\
\hline frequency (day week ${ }^{-1}$ ) & $5.4(1.2)$ \\
\hline intensity $\left(\mathrm{m} \mathrm{sec}^{-1}\right)$ & $2.88(0.66)$ \\
\hline $\mathrm{V}_{5 \mathrm{~km}}\left(\mathrm{~m} \mathrm{sec}^{-1}\right)$ & $4.09(0.57)$ \\
\hline $\mathrm{V}_{10 \mathrm{~km}}\left(\mathrm{~m} \mathrm{sec}^{-1}\right)$ & $3.91(0.58)$ \\
\hline$V_{M}\left(m \sec ^{-1}\right)$ & $3.42(0.53)$ \\
\hline
\end{tabular}

BMI, body mass index; HR, pre-training heart rate; SBP, pre-training systolic blood pressure; DBP, pre-training diastolic blood pressure; $\dot{V}_{2} @ L T$, oxygen uptake $\left(\mathrm{VO}_{2}\right)$ corresponding to lactacte threshold (LT); $\dot{V}_{\mathrm{O}_{2} \text { max }}$, maximal oxygen uptake; $\mathrm{V}_{5 \mathrm{~km}}$, mean running velocity during the best $5-\mathrm{km}$ race; $V_{10 \mathrm{~km}}$, mean running velocity during the best $10-\mathrm{km}$ race; $V_{M}$, mean running velocity during the best marathon race 
Table 2. Independent variables that were significantly correlated with the mean running velocity

$\mathrm{V}_{5 \mathrm{~km}} \quad \dot{V}_{\mathrm{O}_{2}} @ \mathrm{LT}(0.83), \operatorname{Age}(-0.79), \dot{V}_{\mathrm{O}_{2} \max }(0.76)$, distance $(0.45)$

$\mathrm{V}_{10 \mathrm{~km}} \quad \dot{V}_{\mathrm{O}_{2}} @ \mathrm{LT}(0.74)$, Age $(-0.73), \dot{V}_{\mathrm{O}_{2} \max }(0.72)$, distance $(0.29)$

$\mathrm{V}_{\mathrm{M}} \quad \dot{V}_{\mathrm{O}_{2}} @ \mathrm{LT}(0.88)$, Age $(-0.86), \dot{V}_{\mathrm{O}_{2} \max }(0.83)$

Values in parentheses denote correlation coefficients; definitions as in Table 1

Table 3. Linear multiple regression equations

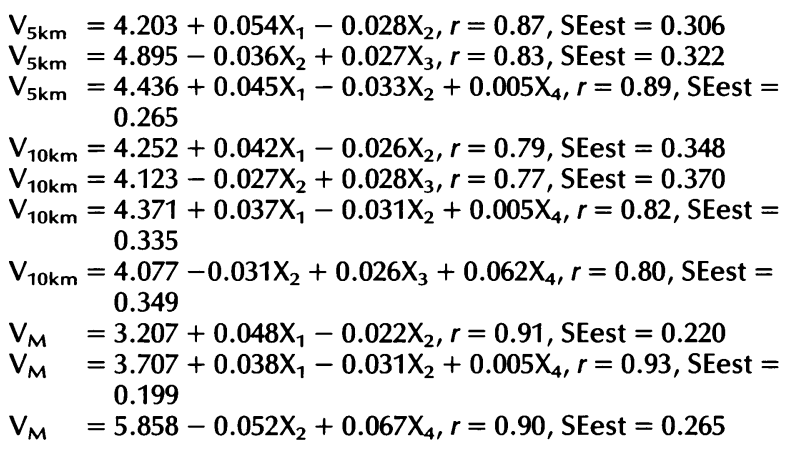

Where $V_{5 \mathrm{~km}}, \mathrm{~V}_{10 \mathrm{~km}}$ and $\mathrm{V}_{\mathrm{M}}$ are the mean running velocity $\left(\mathrm{m} \mathrm{sec}^{-1}\right)$ at $5 \mathrm{~km}, 10 \mathrm{~km}$ and marathon, respectively and $X_{1}=$ $\dot{V}_{\mathrm{O}_{2}} @ \mathrm{LT}\left(\mathrm{ml} \mathrm{kg}^{-1} \mathrm{~min}^{-1}\right), \mathrm{X}_{2}=$ age (year), $\mathrm{X}_{3}=\dot{V}_{\mathrm{O}_{2} \max }\left(\mathrm{ml} \mathrm{kg}^{-1}\right.$ $\left.\min ^{-1}\right)$, and $X_{4}=$ average running duration per workout ( $\mathrm{min}$ )

product-moment correlation analysis showed that $\stackrel{V}{\mathrm{O}_{2}} @ \mathrm{LT}, \dot{V} \mathrm{O}_{2 \max }$ and age were the three independent variables that were correlated most strongly with $\mathrm{V}_{5 \mathrm{~km}}, \mathrm{~V}_{10 \mathrm{~km}}$ and $\mathrm{V}_{\mathrm{M}}$ (Table 2). Associations of other independent variables such as BMI or training characteristics with the running performances were statistically insignificant or only low to moderate.

Table 3 summarizes the linear multiple regression equations, with partial regression coefficients, developed in this study. Variables selected for prediction of the $V_{5 \mathrm{~km}}, V_{10 \mathrm{~km}}$ or $\mathrm{V}_{\mathrm{M}}$, were any two or three prerequisites from $\dot{V O}_{2} @ \mathrm{LT}, \dot{V}_{2}$ max age and average running duration per workout. The SEest for each prediction equation is also included in Table 3, which is the statistic commonly used to quantify the accuracy of a prediction equation.

\section{Discussion}

Although it has previously been suggested that $\dot{V}_{\mathrm{O}_{2} \max }$ is the single best indicator of ERP, more recently, several studies, $81,19,20$ have found that $\dot{V} \mathrm{O}_{2} @ \mathrm{LT}$ is a better predictor of ERP than $\dot{V}_{\mathrm{O}_{2}}$ max Interestingly, Tanaka et al. ${ }^{20}$ reported that even in the improved state in terms of ERP and $\dot{V O}_{2} @ L T$, higher relationships $(r \geqslant 0.75)$ between the ERP and LTrelated variables held up consistently over the 9-month training period. It is of more interest to note that ERP changes were more strongly accounted for by the $\dot{V}_{\mathrm{O}_{2}} @ \mathrm{LT}$ changes, rather than changes in other physiological attributes including $\dot{\mathrm{O}}_{2} \max { }^{20}$. In the present study, high relationships were also found between the $\mathrm{VO}_{2} @ \mathrm{LT}$ and ERP $(r=0.74 \sim 0.88)$ and between $\dot{V}_{\mathrm{O}_{2} \max }$ and ERP $(r=0.72 \sim 0.83)$ at all distances. Therefore, a high $\dot{V}_{\mathrm{O}_{2}} @ \mathrm{LT}$ and/or $\dot{V}_{\mathrm{O}_{2} \max }$ as well as age could be considered, even among older runners, as one of the most influential determinants of performance in distance running and marathon events. The fact that age was found the second most influential variable in predicting ERP may be simply because running ability in general decreases linearly with ageing.

We reported that the ERP of middle-aged and older runners could be predicted with a relatively high accuracy by a single predictor of $\dot{\mathrm{O}}_{2} @ \mathrm{LT}$ or $\mathrm{VO}_{2}$ max or by a combination of either of these predictors with more easily measurable indices such as age, atherogenic index, Katsura index or systolic blood pressure ${ }^{21}$. However, the relationships of the training habits with ERP have not been investigated in middle-aged and older runners. It is necessary to examine the relative contribution of training habit factors as a single entity or in combination, to the ERP. Contrary to our expectations, all variables on the training habits of the subjects, with the exception of weekly running distance, did not show significant correlations with ERP.

In previous investigations ${ }^{4,22-24}$, success in ERP has been found to be related to the training indices which include total workouts and workout days, average running velocity in $\mathrm{m} \mathrm{min}^{-1}$, maximum running distance per week, average distance per workout, average distance per week and total duration and distance of training run. Above all, average distance per workout, average distance per week and total distance run during the 9 weeks preceeding the race were the most powerful factors related to improved race performance ${ }^{22}$. World-class distance runners usually run twice a day and between 110 and $240 \mathrm{~km}^{\text {week }}{ }^{-1}$ for 45-52 weeks year $^{-1,6}$. Less well-accomplished runners train below these levels and it has been recommended that aspiring marathoners train for at least 3 months at progressively greater weekly distances up to an average of $80 \mathrm{~km}^{\text {week }}{ }^{-1}$ to ensure completion of a marathon race ${ }^{23}$. Slovic ${ }^{24}$ has predicted that $35-50 \%$ of the variation in ERP is attributed to the maximum miles run in 1 week and $34-49 \%$ of the variation in ERP to the total miles run in the 8 weeks prior to the race. In the present cross-sectional data, correlations of training characteristics with ERP were statistically insignificant or only low to moderate (average distance per week; $r=0.29 \sim 0.45$ ). Therefore, it is difficult to estimate ERP with any high accuracy from training habits in the middle-aged and older runners as compared with younger subjects. In future, however, it is important to analyse in more detail the relationship among ERP and training habits in longitudinal data for middle-aged and older runners.

When $\dot{V}_{\mathrm{O}_{2}} @ \mathrm{LT}$, age and one more factor (for example, average running duration per day, weight or BMI) were entered into stepwise multiple regression analysis, they accounted for $79 \%$ and $67 \%$ of the variance in $\mathrm{V}_{5 \mathrm{~km}}$ and $\mathrm{V}_{10 \mathrm{~km}}$ respectively, which were not significantly different from $76 \%$ and $63 \%$ accounted for by a combination of $\dot{V}_{\mathrm{O}_{2}} @ \mathrm{LT}$ and age. It is, therefore, suggested that the addition of another variable does not raise predictive accuracy to a 
statistically meaningful level. The SEest of the predicted ERP seems to be small, particularly in view of the heterogeneous nature of the sample studied.

In conclusion, we suggest that ERP of middle-aged and older runners with heterogeneous training habits can be predicted with high accuracy by $\dot{V} \mathrm{O}_{2} @ \mathrm{LT}$ and age or possibly a combination of these variables plus average running duration per workout. The prediction equations developed in this study could be expanded for use in a greater population of middleaged and older runners, from the moderately to the highly trained.

\section{References}

1 Costill DL. The relationship between selected physiological variables and distance running performance. J Sports Med Phys Fitness 1967; 7: 61-6.

2 Costill DL, Thomason H, Roberts E. Fractional utilization of aerobic capacity during distance running. Med Sci Sports Exerc 1973; 51: 248-52.

3 Allen WK, Seals DR, Hurley BF, Ehsani AA, Hagberg JM. Lactate threshold and distance-running performance in young and older endurance athletes. J Appl Physiol 1985; 58: 1281-4.

4 Conley DL, Krahenbuhl GS. Running economy and distance running performance of highly trained athletes. Med Sci Sports Exerc; 1980; 12: 357-60.

5 Tanaka K, Takeshima N, Kato T, Niihata S, Ueda K. Critical determinants of endurance performance in middle-aged and elderly endurance runners with heterogeneous training habits. Eur J Appl Physiol 1990; 59: 443-9.

6 Pollock ML. Submaximal and maximal working capacity of elite distance runners. Part I: cardiorespiratory aspects. Ann NY Acad Sci 1977; 301: 310-22.

7 Londeree BR, Ames A. Maximal steady state versus state of conditioning. Eur J Appl Physiol 1975; 34: 269-78.

8 Farrell TA, Wilmore JH, Coyle EF, Billing JE, Costill DL. Plasma lactate accumulation and distance running performance. Med Sci Sports 1979; 11: 338-44.

9 LaFontaine TP, Londeree BR, Spath WK. The maximal steady state versus selected running events. Med Sci Sport Exerc 1981; 13: 190-3.
10 Kumagai S, Tanaka K, Matsuura Y, Matsuzaka A, Hirakoba K, Asano K. Relationships of the anaerobic threshold with the $5 \mathrm{~km}, 10 \mathrm{~km}$, and 10 mile races. Eur J Appl Physiol 1982; 49: 13-23.

11 Hagberg JM, Coyle EF. Physiological determinants of endurance performance as studied in competitive racewalkers. Med Sci Sports Exerc 1983; 15: 287-9.

12 Tanaka K, Matsuura Y. Marathon performance, anaerobic threshold and onset of blood lactate accumulation. J Appl Physiol 1984; 57: 640-3.

13 Fay L, Londeree BR, LaFontaine TP, Volek MR. Physiological parameters related to distance running performance in female athletes. Med Sci Sports Exerc 1989; 21: 319-24.

14 Slovic P. Empirical study of training and performance in the marathon. Res Quart 1977; 48: 769-77.

15 Brozek J, Grande F, Anderson JT, Keys A. Densitometric analysis of body composition: review of some quantitative assumptions. Ann New York Acad Sci 1963; 110: 113-40.

16 Nagamine S, Nuzuki S. Anthropometric and body composition of Japanese young men and women. Hum Biol 1964; 36: 8-15.

17 Nakadomo F, Tanaka K, Watanabe H, Fukuda T. Rapid blood lactate determination with a semi-automatic lactate analyzer. Jpn J Sports Sci 1985; 4: 980-2. (in Japanese with English abstract)

18 Beaver WL, Wasserman K, Whipp BJ. Improved detection of lactate threshold during exercise using a log-log transformation. J Appl Physiol 1985; 59: 1936-40.

19 Tanaka K, Matsuura Y, Kumagai S, Matsuzaka A, Hirakoba K, Asano K. Relationships of anaerobic threshold and onset of blood lactate accumulation with endurance performance. Eur J Appl Physiol 1983; 52: 51-6.

20 Tanaka K, Matsuura Y, Matsuzaka A, Hirakoba K, Kumagai S, Son-O S, Asano K. A longitudinal assessment of anaerobic threshold and distance-running performance. Med Sci Sports Exerc 1984; 16: 278-82.

21 Tanaka K. Lactate-related factors as a critical determinant of endurance. Ann Physiol Anthropol 1990; 9: 191-202.

22 Hagan RD, Smith MG, Gettman LR. Marathon performance in relation to maximal aerobic power and training indices. Med Sci Sports Exerc 1981; 13: 185-9.

23 Henderson J, ed. The Complete Marathoner. Mountain View, CA, USA: World Publications, 1978; 15.

24 Slovic P. What makes a marathoner? Runner's World 1973; 8: 16-18. 